\title{
Effects of electrocutaneous ready-signal variation on visual reaction time
}

ISAAC BEHAR, US ARMY MEDICAL RESEARCH LABORATORY, FORT KNOX, KENTUCKY JOEL S. WARM, ${ }^{1}$ UNIVERSITY OF LOUISVILLE

Two ready-signal variables (direction of change in electrocutaneous stimulation and method of presentation: "trace" or "delayed") were combined in a 2 by 2 by $S s$ design. Neither variable produced a significant main effect but yielded a highly significant interaction. Results were interpreted in terms of arousal, intersensory, and conditioning explanations of ready-signal effects.

Recent studies have demonstrated that the ready signal in the reaction time (RT) experiment, in addition to reducing the temporal uncertainty regarding the onset of the response signal, may also facilitate or impair RT, depending upon the temporal and intensive properties of the particular ready signal. Thus, Geblewiczowa (1963) found that two closely spaced ready signals resulted in shorter RTs than did a single ready signal or two which were more widely separated in time. Behar and Adams (1966) found an inverse relation between ready signal intensity and RT, and also shorter RTs with "delayed" than with "trace" presentation of the ready signal. That the ready signal intensity effect depends upon the magnitude of stimulus change from the intertrial intensity, rather than the intensity per se, was shown by Adams and Behar (1966). Finally, Furedy (1966) found impairment of RT when the ready signal (air puff) overlapped with the presentation of the response signal.

Three types of explanation have been suggested to account for RT ready signal effects. Geblewiczowa (1963) hypothesized an arousal effect of the ready signal mediated by the reticular activating system. Furedy (1966) proposed that the perception of the response signal may be masked by the accessory stimulation provided by the ready signal. The third view, that of Behar and Adams (1966), proposed that preparatory responses become conditioned to the ready signal. Hence, the more effective the ready signal is as a $\mathrm{CS}$, the greater is response readiness, and the shorter is RT.

One of the difficulties in choosing among explanations based upon arousal, intersensory, or conditioning effects is the fact that they are not mutually exclusive. Brebner (1963), for example, attempted to account for intersensory effects themselves in terms of increased arousal, and Behar and Adams (1966) considered arousal to be one of the responses which may become conditioned to the onset of the ready signal. The other difficulty derives from the very modest empirical base provided by existing studies of ready signal variation. No data exist, for example, concerning the modality generality of obtained effects. In all but one previous study, auditory ready signals were used. Our purpose in the present study was to determine whether ready signals presented in another "closely coupled" modality, using electrocutaneous stimulation, would produce comparable effects.

\section{METHOD}

Two ready signal variables were combined in a 2 by 2 by Subjects design. One variable was direction of change in electrocutaneous stimulation, i.e., whether it was an increase from a zero intertrial level or a decrease to zero from a relatively high intertrial level. The other variable was method of presentation of the ready signal, i.e., whether trace or delayed. These ready signal conditions are schematized in Fig. 1.

\section{Subjects}

Twelve men between the ages of 17 and 22 years volunteered as Ss.

\section{Apparatus}

Each $\mathrm{S}$ was tested individually in a partially sound treated room adjacent to that occupied by the $E$ and the control equipment. The electrocutaneous ready signal stimulus consisted of the output of a GrasonStadler white noise generator, amplified by a Dynakit amplifier, and delivered to the $S$ from Triad $S-41 X$ and $A-42 Z$ transformers. Peak to peak current was about $4.0 \mathrm{~mA}$, a level which was uncomfortable but not painful. Electrodes consisted of two metal plates about 2 in. $x 4$ in.; the $S$ rested the finger tips of

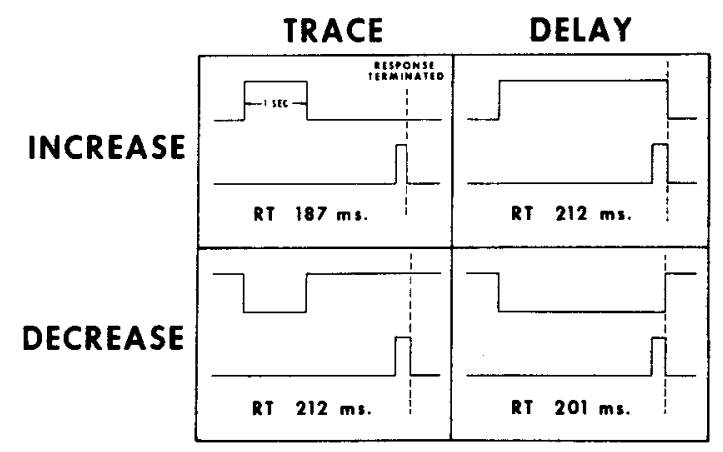

Fig. 1. Schematization of experimental conditions and associated RTs. Upper trace in each panel depicts the ready signal while the lower trace corresponds to the response signal. 
the nonpreferred hand on one plate while the heel of the hand rested on the other. An elastic band maintained good contact between hand and electrodes. The visual response signal was always an increase in luminance from 7 to $18 \mathrm{ft}-\mathrm{L}$ of a fluorescent lamp which was masked to subtend a visual angle of about $1^{\circ}$. Recycling Hunter timers determined the time of onset of all stimuli. Reaction times were measured to $1 \mathrm{msec}$ using a Hunter Klockounter.

\section{Procedure}

Each $\mathrm{S}$ was tested in three sessions, each at least one day apart. The first was a practice session in which the $S$ received 24 trials, six with each ready signal condition: trace-increase, trace-decrease, delay-increase, and delay-decrease. During the first experimental day six Ss received only "increase" trials (counterbalanced between trace and delay trials), while the other six received only "decrease" trials (counterbalanced for trace and delay). On the second experimental day, the conditions were reversed. On each of the test days the Ss received six warm-up trials and 48 test trials, 24 each of trace and delay.

For the trace conditions, the change in electrocutaneous stimulation (increase or decrease) lasted for $1 \mathrm{sec}$, while for the delay conditions, the change persisted throughout the foreperiod and overlapped with the response signal. The response signal was response terminated in all conditions and, in addition, in the delay conditions the ready signals were response terminated. The foreperiod, measured from the onset of the change in the electrocutaneous stimulus to the increase in luminance of the response signal, was either $2.1,2.4$, or $2.7 \mathrm{sec}$ on any trial. Trials were presented every $20 \mathrm{sec}$.

\section{RESULTS AND DISCUSSION}

The data used for analysis were the arithmetic means of the 20 trials remaining after the two longest and shortest reaction times were excluded for each condition for each $\mathrm{S}$. The group mean reaction times for the four conditions are presented in Fig. 1. It can be seen that RTs varied considerably among the four conditions. Neither the differences between method of presentation (trace or delay), nor direction of energy change were significant; however, the interaction between these variables is highly significant ( $F=18.88, \mathrm{df}=1 / 11, \mathrm{p}<.005)$.

The explanation of the significant interaction in the absence of significant main effects may be related to that fact that in the two conditions representing the diagonal yielding faster reaction times, the electrocutaneous stimulus is off at the moment at which the response signal is presented, and alternatively, that in the two conditions in which
RTs were relatively slow, the electrocutaneous stimulus was on. One possible interpretation of this result is that electrocutaneous stimulation, simultaneous with the presentation of the response signal, somehow serves to degrade performance. This result is consistent with that obtained by Furedy (1966) and lends support to his explanation based upon intersensory masking. Plausibility for such an interpretation derives from studies of Halliday and Mingay (1961) and Novak (1965) in which raised perceptual thresholds have been directly observed with tactual accessory stimulation.

An alternative interpretation of the significant interaction is based upon facilitation of $\mathrm{RT}$ through differential arousal (Geblewiczowa, 1963). According to this view, since faster RTs occurred when the response signal followed shortly after the termination of the electrocutaneous stimulus (trace-increase and delay-decrease conditions), slower. when it followed the onset of the electrocutaneous stimulus (tracedecrease and delay-increase conditions), it is assumed that offset of electrocutaneous stimulation produced a more nearly optimal level of arousal than did the onset of electrocutaneous stimulation. The extension of this interpretation, within the context of the conditioning model of reaction time (Behar \& Adams, 1966) argues for more rapid conditioning, or a higher level of elicitation of already conditioned, preparatory responses, with electrocutaneous offset than with onset. Needless to say, this interpretation requires independent verification.

\section{References}

Adams, C. K., \& Behar, 1. Stimulus change properties of the RT ready signal. Psychon. Sci., 1966, 6, 389-390.

Behar, I., \& Adams, C. K. Some properties of the reaction-time ready-signal. Amer. J. Psychol., 1966, 79, 419-426.

Brebner, J. The bisensory presentation of information. I. A review of experiments on sensory interaction. Flying Personnel Research Committee Report No. FPRC/1209(a), 1963.

Furedy, J. J. Reaction time as an index of masking and the effect of check trials on thoughtful subjects. Austr. J. Psychol., 1966 , 18, 255-261.

Geblewiczowa, Maria. Influence of the number of warning signals and of the intervals between them on simple reaction-time. Acta Psychol., 1963, 21, 40-48.

Halliday, A. M., \& Mingay, Rosemary. Retroactive raising of a sensory threshold by a contralateral stimulus. Quart. J. exp. Psychol., 1961, 13, 1-11.

Novak, S. The effect of electrocutaneous digital stimulation on the detection of single and double flashes of light. Psychol. Monogr., $1965,79,1-19$ (Whole No. 608).

\section{Note}

1. Supported in part by the U.S. Army Medical Research and Development Command, Department of the Army, under Research Contract No. DA-49-193-MD-2918, "Stimulus Factors in Human Timing Behavior." The authors are indebted to Mr. Ronald McCray for technical assistance.

(Accepted for publication July 5, 1967.) 